\title{
LETRAMENTOS DE SOBREVIVÊNCIA EM REDES DIGITAIS: CAMINHOS POSSÍVEIS NA LUTA POR DIREITOS HUMANOS
}

\section{LITERACIES OF SURVIVAL IN DIGITAL NETWORKS: POSSIBLE DIRECTIONS FOR HUMAN RIGHTS STRUGGLES}

\author{
Junot de Oliveira Maia*
}

\section{RESUMO}

O presente trabalho propõe um percurso analítico sobre como letramentos de sobrevivência questionam, desestabilizam e, em algumas situações, rompem a hegemonia instaurada a partir de escritas produzidas por setores poderosos da sociedade brasileira, como é o caso das grandes corporações de mídias e de seus enunciados que visam a criminalizar os moradores de favela da cidade carioca. Nesse sentido, conduzo a discussão até apresentar o conceito de letramentos de sobrevivência para, com base nele, refletir sobre a maneira como Mariluce Mariá e Cléber Santos, moradores do Complexo do Alemão/RJ envolvidos em ações de participação cidadã pertinentes ao território em que vivem, usam suas redes digitais para postarem enunciados capazes de ampliar seu poder de ação na luta por direitos humanos. Faço isso, sobretudo, com base em dois eventos específicos: na entrevista concedida pelo casal no curso "Sobreviver, sobrevivências", oferecido no curso de Pós-Graduação em Antropologia Social do Museu Nacional em 2015, e no tuitaço \#SOSComplexodoAlemão, de cuja organização Mariluce e Cléber participaram. Por meio deles, pretendo denotar como os moradores de favela conseguem usar suas redes digitais para produzir textos que se contrapõem às narrativas hegemônicas que entendem a favela como um entrave à dinâmica urbana. Minhas interpretações são pautadas no trabalho de campo que realizo no mencionado conjunto de favelas desde 2013, classificado em trabalhos anteriores como uma etnografia de fronteira.

Palavras-chave: Letramentos; Sobrevivência; Redes digitais; Direitos humanos.

\section{ABSTRACT}

This paper proposes an analytical course on how literacies of survival question, destabilize and, sometimes break the hegemony established by writings produced by powerful sectors of Brazilian society, such as the largest media corporations and the statements produced by them to criminalize favelas dwellers in Rio de Janeiro. In this sense, I lead the discussion to present the concept of literacies of survival to based on it reflect on how Mariluce Mariá and Cléber Santos, residents of Complexo do Alemão - a huge complex of favelas in Rio de Janeiro - involved in actions of citizen participation in the territory in which

\footnotetext{
* Instituto Federal de Educação, Ciência e Tecnologia de São Paulo, São Paulo (SP), Brasil. junotmaia@ gmail.com
} 
they live, use their digital networks to post statements capable of broadening their power of action in struggles aiming to human rights. Above all, I do it based on two specific events: on the interview granted by the couple in the course "Survival, survivals", from the postgradute program in Social Anthropology of the National Museum of Brazil in 2015, and on the hashtag \#SOSComplexodoAlemão, whose planning Mariluce and Cléber participated of. Through those events, I mean to denote how favelas dwellers can use their digital networks to produce texts that counteract then hegemonic narratives that consider favelas an obstruction to the urban dynamics. My interpretations are based on the fieldwork I have undertaken in Complexo do Alemão since 2013, classified in prior reflections of mine as a border ethnography.

Keywords: Literacies; Survival; Digital networks; Human rights.

\section{REDES DIGITAIS E DIREITOS HUMANOS: UM COMEÇO DE CONVERSA PARA SE PENSAR SOBRE LETRAMENTOS}

As tecnologias digitais, sobretudo quando conectadas à rede mundial de computadores, têm mostrado cada vez mais o seu potencial para promover ampla circulação de enunciados diversos por vias e conexões antes inimagináveis. Isso se dá principalmente pelo fato de que, com o advento da internet, todo indivíduo conectado pode se tornar um veículo de comunicação, uma mídia, produzindo, publicando e filtrando (ou não) suas postagens. Ao refletir sobre esse fato, Clay Shirky (2012 [2008]), especialista em estudos sobre mídias digitais e sobre topologias de redes, afirma que

[n] ossas ferramentas sociais removem obstáculos mais antigos à expressão pública, eliminando assim os gargalos que caracterizavam os meios de comunicação de massa. O resultado é a amadorização em massa de esforços antes reservados a profissionais da mídia (SHIRKY, 2012 [2008], p. 51).

Desse modo, a internet é entendida como um espaço muito menos burocrático de comunicação e, por conseguinte, de compartilhamento de conteúdos. Esse fator, é claro, favorece demais a veiculação de enunciados e de narrativas por parte de qualquer usuário, mas se torna ainda mais interessante no caso daqueles que tiveram historicamente poucas oportunidades de terem suas pautas abordadas pelas grandes corporações de mídia, agentes históricos de monopolização no mercado de circulação de informações.

Acho interessante, pois, chamar atenção para um caso emblemático em que as tecnologias digitais foram utilizadas para fazer circular textos em escalas mais amplas, dando grande visibilidade para um acontecimento que, costumeiramente, não teria a mesma relevância nos veículos tradicionais de mídia. Trata-se do desaparecimento do pedreiro Amarildo Dias de Souza durante a operação Paz Armada, deflagrada na 
Rocinha no dia 14 de julho de 2013. Transcrevo abaixo a reportagem sobre o fato, publicada quatro dias depois do ocorrido, para melhor contextualização acerca do desaparecimento de Amarildo.

\section{POLÍCIA INVESTIGA DESAPARECIMENTO DE PEDREIRO NA ROCINHA, NO RIO}

O pedreiro Amarildo Dias de Souza, 47, morador da Favela da Rocinha, na zona sul do Rio, está desaparecido desde a noite de domingo (14) quando foi levado por policiais militares à sede da UPP (Unidade de Polícia Pacificadora). Na quarta (17) à noite, moradores da favela fizeram uma passeata em protesto contra o desaparecimento.

Ontem à tarde, a família de Souza se reuniu com o Secretário de Segurança Pública do Rio, José Mariano Beltrame; o comandante da UPP local, o major Edson Santos; o delegado da 15a DP (Gávea), Orlando Zaccone; e o presidente da Comissão de Direitos Humanos da ALERJ (Assembleia Legislativa), o deputado Marcelo Freixo (PSOL-RJ).

De acordo com os parentes do pedreiro, ele chegava de uma pescaria quando foi levado para uma averiguação na sede da UPP. Desde então, está desaparecido,

Já o Comando da UPP da Rocinha informou que o rapaz foi levado à UPP por ser suspeito de envolvimento com o tráfico de drogas no local, mas como sua suposta ligação não foi confirmada, ele foi logo liberado.

Policiais da 15a DP vão buscar imagens do sistema de câmeras da Rocinha para saber o que aconteceu com o pedreiro após deixar a área administrativa da UPP. A favela possui um sistema com 84 câmeras instaladas em 14 pontos considerados estratégicos da comunidade. Desde sábado, a Polícia Civil, com o apoio dos policiais da UPP, tenta cumprir 58 mandados de prisão por tráfico de drogas, na favela da Rocinha. Até o momento, 27 foram presas.

A operação Paz Armada, deflagrada no sábado pelas polícias Civil e Militar, descobriu após 3 meses de investigação que, um ano e meio após a ocupação da favela, ainda há 100 pontos de venda de drogas em funcionamento na Rocinha. (FOLHA DE S. PAULO, 2013, s/p)

Naquela ocasião, a partir do momento em que passou a ficar evidente o envolvimento de policiais no desaparecimento não explicado do pedreiro, não foram poucas as manifestações indignadas, de autoria de diferentes cidadãos, que passaram a circular pelos sites de redes sociais mais utilizados no país, em especial o Facebook e o twitter. Além disso, a revolta de parcela considerável da população com o caso de Amarildo ganhava ainda mais notoriedade no contexto de efervescência política e de pretensa luta contra a corrupção que caracterizava o Brasil daqueles tempos, período que ficou conhecido como jornadas de junbo (SECCO, 2013).

Em decorrência de tamanhas popularidade e visibilidade (MAIA; BRAGA, 2017) alcançada em nível nacional, muitas postagens passaram a mencionar a basbtag ${ }^{1}$ \# somostodosamarildo a fim de protestar contra o desaparecimento do pedreiro e, de forma mais ampla, clamar por justiça diante dos inúmeros casos de abuso de poder associados

1. As basbtags podem ser entendidas sucintamente como mecanismos de indexação de palavras-chave para o agrupamento e destaque de conteúdos semelhantes. 
à Polícia Militar atuante na cidade do Rio de Janeiro (PMERJ). O apelo a basbtags deve ser destacado na medida em que trabalhos como o de Bruns e Burgess (2011) nos fazem acatar que seu uso, além de criar uma rede de pessoas interessadas em um mesmo tópico - no caso, a morte de Amarildo -, as quais podem interagir e, desse modo, buscar alternativas de mobilização, garante que, quanto maior for o número de usuários que a mencionarem, maior será a notoriedade que ela mesma ganhará dentro da própria rede social estabelecida, atingindo os chamados trending topics ${ }^{2}$.

A título de ilustrar as reações que circularam à época, registro o post feito pela Mídia NINJA 3 relativo à campanha por eles promovida em parceria com artistas, ativistas e juristas para cobrar explicações do poder público referentes ao caso, além de levantar fundos para o Instituto Defensores dos Direitos Humanos $(\mathrm{DDH})$ e para a família do pedreiro Amarildo.

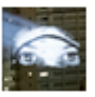

NINJA

7 de outubro de 2013 .

\section{\#SomosTodosAmarildo}

Foi lançada hoje à tarde a campanha "Somos Todos Amarildo". Uma iniciativa de artistas, ativistas e juristas como o objetivo de levantar fundos para um novo lar para a família de Amarildo e para o Instituto de Defensores dos Direitos Humanos.

E que pretende tratar de uma das mais tristes questões em nosso país: os milhares de mortos e desaparecidos em ações policiais em pleno regime democrático.

Amanhã haverá um leilão de arte e de objetos doados por diversos artistas.

No dia 20 de novembro, um show de Caetano Veloso e Marisa Monte no Circo Voador, Rio e Janeiro, como toda a renda revertida para o projeto. E, no dia 30 de novembro, um ato na praia do Arpoador.

No vídeo compartilhado aqui, o contexto, a campanha e depoimentos de familiares de Amarildo, além de juristas e amigos que estiveram na Rocinha e acompanham o caso de perto.

Assista. E espalhe com \#SomosTodosAmarildo

Figura 1. Mídia NINJA promove a campanha \#somostodosamarildo. Fonte: Mídia NINJA4.

2. Em português, a tradução literal de trending topics é de tópicos em tendência, o que equivale à ideia de assuntos do momento.

3. A Mídia NINJA (Narrativas Independentes, Jornalismo e Ação) corresponde a uma rede de comunicadores que produzem e distribuem informação em movimento, agindo e comunicando, a partir de uma lógica colaborativa de criação e compartilhamento de conteúdos. Para maiores detalhes, acessar https://ninja.oximity.com/partner/ninja/about. Último acesso em 06 de Fevereiro de 2018.

4. Disponível em: https://www.facebook.com/MidiaNINJA/posts/233071476851005. Último acesso em 10 de Abril de 2017. 
Não faço essa menção sem reconhecer que o sucesso da campanha também se concretizou em função da aliança estabelecida entre a rede alternativa de comunicadores e agentes poderosos que se relacionam com as mídias corporativas, caso da produtora cultural Paula Lavigne, que, desde o início, foi uma das pessoas mais atuantes e engajadas nessa empreitada. Mesmo assim, as postagens que cobravam reação do poder público foram eficazes: podem ter sido feitas na Rocinha ou em São Conrado, no Leblon ou no Complexo do Alemão, no Rio de Janeiro ou no Acre, mas, mesmo destoantes em seus pontos de partida, resultaram em popularidade e visibilidade para a questão da violência que massacra minorias, em cobrança para resolução desse caso e de outros de mesma natureza e em ajuda direta para a família de Amarildo, fortemente abalada por sua morte. Esse fato, portanto, é digno de destaque principalmente por, mesmo diante das questionáveis políticas de privacidade e de uso de dados do Facebook e do twitter, representar de forma metonímica o poder das redes sociais digitais como ferramentas alternativas às grandes corporações de mídia na luta por direitos humanos das minorias oprimidas, muitas vezes violentadas mortalmente, sobretudo nos subúrbios e periferias urbanos brasileiros.

Ocorrido no dia 2 de abril de 2015, o caso da morte de Eduardo de Jesus Ferreira, morador do Complexo do Alemão de 10 anos de idade, é exemplo de violação de direitos humanos ocorrida em contexto de periferia urbana em que as mídias digitais exerceram um papel relevante de questionamento e denúncia de arbitrariedades praticadas pelos agentes de UPPs, mas que, por outro lado, acabou evidenciando as limitações desses recursos quando confrontadas com outras dinâmicas de poder. O inquérito conduzido pela Divisão de Homicídios da Polícia Civil para investigar a ocorrência chegou à conclusão de que a morte de Eduardo teria se dado pela infelicidade de o garoto estar sentado justamente na linha de tiro dos policiais, os quais, agindo em legítima defesa, alvejavam os varejistas de drogas ${ }^{5}$ com que estavam em conflito. Contudo, conforme consta no laudo que sustentou

5. Justamente por entender o poder performativo da linguagem (AUSTIN, 1962), inclusive no que tange à construção e reforço de estereótipos sociais, faço questão de registrar aqui que a preferência pelo uso de construções similares a "varejistas do comércio de drogas ilícitas" a traficantes se estabelece como indício de reflexões advindas da Criminologia Crítica e que permearam as experiências por que passei ao longo do meu trabalho de campo. Trabalhos como os de Vera Malaguti Batista (2011) e de Orlando Zaccone D’Elia Filho (2007) lançaram holofotes para o fato de que a complexa estruturação do tráfico de drogas tem a favela como o fio solto de sua composição, elemento final de uma trama cujos pontos menos valorizados da cadeia exercem pouca ou nenhuma influência sobre toda a sua dinâmica. 
esse mesmo inquérito, classificado como uma aberração pela Anistia Internacional ${ }^{6}$, os tiros partiram de uma distância de 5 metros, a qual seria consideravelmente pequena para que o policial não conseguisse distinguir o seu alvo e evitar a tragédia.

A compreensão do acontecimento como um homicídio decorrente de intervenção policial, nomenclatura adotada pela mesma Anistia para casos como esse, é coerente com os relatos dos próprios moradores e, principalmente, da mãe de Eduardo: segundo Terezinha Maria de Jesus, o que ocorreu foi a execução de seu filho enquanto ele brincava com um celular na porta de sua própria casa. A ação teria sido, pois, uma demonstração da onipotência dos policiais em pleno território a fim de colocar medo nos moradores que estavam ao redor e de mostrar aos envolvidos com o comércio ilegal de drogas as atrocidades que a própria polícia seria capaz de praticar. A certeza de impunidade por parte do agente da UPP era tão grande que, de acordo com testemunhas, ao ser agredido verbalmente pela mãe do jovem assassinado, ele teria colocado o rifle em sua cabeça e respondido a ela, sem qualquer tipo de autocensura, que, se não ficasse quieta, teria o mesmo fim de Eduardo: "[a]ssim como eu matei o seu filho, eu posso muito bem te matar"7 (SUSSMAN, 2015).

Foram muitas as manifestações de revolta decorrentes da execução do menino e das conclusões relativas ao processo, muitas delas registradas nas redes digitais por meio de basbtags que se referiam de algum modo a Eduardo. Infelizmente, o alcance dessas iniciativas não foi o mesmo atingido pelo caso de Amarildo, o que culminou em uma pressão pouco efetiva durante o desenrolar das investigações. $\mathrm{O}$ processo, enfim, inocentou todos os policiais envolvidos e acabou sendo arquivado no dia 29 de novembro de 2016, conforme reportagem do portal de notícias G1 (COELHO, 2016). Traumatizados, os pais do garoto retornaram ao seu estado de origem, o Piauí, a fim de recomeçar suas vidas distantes do lugar em que puderam ver seu filho pela última vez.

O contraste, pois, entre as situações do pedreiro e do menino de dez anos esclarecem como essas campanhas são impulsionadas pelas potencialidades dos meios digitais, mas, ainda assim, dependem da integração entre eles e outros fatores sociais estratégicos e contingenciais para lograr algum êxito em níveis estruturais mais amplos. Essa afirmação encontra respaldo principalmente no fato de que casos

6. Disponível em: https://oglobo.globo.com/rio/anistia-inquerito-sobre-morte-de-crianca-no-alemao-aberracao-17952704. Último acesso em 12 de março de 2018.

7. Declaração enunciada pela mãe de Eduardo e extraída do documentário "In Rio, pacification without peace", produzido por Nadia Sussman para o New York Times. Disponível em: https:// www.nytimes.com/video/world/americas/100000004021224/in-rio-pacification-without-peace. html. Ultimo acesso em 12 de março de 2018. 
como os de Eduardo, encerrados com as manchas da impunidade e do silenciamento, são muito mais comuns do que aqueles em que a Justiça é tão pressionada que acaba correspondendo a grande parte das expectativas dos cidadãos, como ocorreu no exemplo de Amarildo.

Interessante ressaltar o fato de que campanhas como essas, mesmo não alcançando plenamente seus anseios por justiça, acabam colocando em xeque julgamentos que partem dos grupos de poder para estigmatizar sujeitos socialmente minorizados. Não raro, por exemplo, é possível ouvir máximas produzidas em função de posicionamentos ideologicamente autoritários como "Direitos humanos para humanos direitos" quando tratamos de moradores de favela, historicamente criminalizados por discursos hegemônicos que reforçam marginalizações. Contrapondo-se também a essas criminalizações, Pâmella Passos e Adriana Facina, na cartilha Cultura Popular e Direitos Humanos (2014), lançada pelo DDH, propõem uma reflexão importante sobre a ideia equivocada de que pensar em direitos humanos é apoiar o banditismo.

"Direitos humanos é defender bandidos!". Essa é a principal argumentação do senso comum. No entanto, os direitos humanos baseiam-se na premissa de que todas as vidas precisam ser protegidas. Nessa conjuntura, o Estado, através da lei e de seus agentes, deveria ter o papel de garantir a vida e não de praticar a morte, como vem acontecendo. (PASSOS, FACINA, 2014, p. 8)

Nesse excerto, é perceptível, por um lado, o uso de uma linguagem mais combativa, alicerce para a produção de enunciados que digam claramente ao morador que o papel do Estado não é o de violentar a população, mas sim o de defendê-la daqueles que agem em desacordo com suas normas. Essa escrita, sem dúvidas, cumpre sua função de conscientização sobre direitos humanos e culturais em pleno território. Reconheço, por outro lado, que o argumento das antropólogas Veena Das e Deborah Poole (2004) de que o Estado deve ser compreendido também à luz de suas margens, e não exclusivamente sob uma lógica centralizadora e homogeneizante, é fundamental para um entendimento mais aprofundado acerca da fragmentação de sua estrutura e das múltiplas formas de atuação daqueles que o compõem.

Nesse sentido, é preciso fazer a ressalva de que o Estado está, também, presente no território por meio de pesquisadores, de políticos, de juristas, de defensores, enfim, de diferentes agentes que estão sob sua tutela e que não necessariamente simbolizam a violência a partir de suas performances. A etnografia realizada pelo sociólogo Bruno Coutinho de Souza Oliveira, registrada em sua tese de doutorado, por exemplo, foi motivada justamente por sua atuação como gestor territorial 
durante a implantação do chamado PAC-Social, iniciativa de cunho social vinculada ao programa PAC-Favelas ${ }^{8}$. Contudo, se esse mesmo Estado, como apontado por Das e Poole (2004), passa a ser responsável por mortes, extermínios e execuções, ele deve ter sua postura questionada e combatida, já que esse definitivamente não é o seu papel.

Um Estado que traz a punição como característica intrínseca, aliás, se alinha à dinâmica de um Estado de Polícia, tal como o descreve o criminologista argentino Eugenio Raúl Zaffaroni. Para tal estudioso, um Estado como esse alicerça e fortalece a autoridade arbitrária em detrimento da vida, valor sine qua non para os preceitos de um Estado de Direito. Sobre isso, outro criminologista argentino, Lucas Crisafulli, (2016) esclarece que,

[p]ara Zaffaroni (2002), existe uma tensão constante e ainda não resolvida entre um Estado de Direito e um Estado de Polícia. No primeiro deles, o bem é determinado pela maioria, respeitando os direitos da minoria e, assim, mantendo o poder punitivo controlado. No segundo modelo, é a classe dominante que, mesmo contra a maioria, determina o bem e o torna lei. É aqui que o poder punitivo se descontrola. O Estado de Direito preserva a vida. O Estado de Polícia preserva a autoridade, inclusive contra as vidas de um grupo. Sem o filtro que o direito penal pode exercer, sem sua missão deslegitimadora do poder punitivo, sem seus propósitos de redução da seletividade e de contenção do poder de castigar, o poder se dissolve e começam os massacres. ${ }^{9}$ (CRISAFULLI, 2016, p. 35).

Em verdade, os moradores de subúrbios e favelas brasileiros, sobretudo no Rio de Janeiro, sabem que essa mencionada tensão entre os dois modelos estatais favorece, de inúmeras formas, a atuação do Estado de Polícia, mesmo diante do cinismo de vozes oficiais que insistem em afirmar que o Brasil se caracteriza unanimemente pela prevalência do Estado de Direito. Não é sem razão, portanto, que instituições repressoras vinculadas ao governo fluminense, caso da Polícia

8. Anunciado em 2007, o Programa de Aceleração do Crescimento, conhecido como PAC, foi a grande iniciativa do governo de Luiz Inácio Lula da Silva para impulsionar o crescimento da economia nacional. Especificamente, sua modalidade direcionada às periferias e subúrbios urbanos brasileiros foi denominada PAC-Favelas. Para maiores detalhes, sugiro a leitura da tese de Bruno Coutinho de Souza Oliveira, intitulada "Não tem essa de separação, aqui é tudo Complexo do Alemão!": uma etnografia dos espaços urbanos em um conjunto residencial no Rio de Janeiro (OLIVEIRA, 2018).

9. [p]ara Zaffaroni (2002), existe una tensión constante y dialéctica aún no resuelta entre un Estado de Derecho y un Estado de Policía. En el primero de ellos lo bueno lo determina la mayoría respetando los derechos de la minoría y el poder punitivo se encuentra contenido. En el segundo modelo, es la clase dominante la que, incluso contra la mayoría, determina lo bueno y lo hace ley; aquí el poder punitivo se descontrola. El Estado de Derecho preserva la vida. El Estado de Policía preserva la autoridad, incluso contra la vida de un grupo. Sin el filtro que el derecho penal puede ejercer, sin su misión deslegitimante del poder punitivo, sin sus intentos de reducción de la selectividad y contención del poder de castigar, el poder punitivo se desbanda y comienzan los masacres (CRISAFULLI, 2016, p. 35). Tradução minha. 
Militar (PMERJ) e do Batalhão de Operações Policiais Especiais (BOPE) ${ }^{10}$, têm sido alvo de constantes denúncias de violação de direitos humanos por parte de organizações que trabalham com esse tema, como é o caso da Organização das Nações Unidas (ONU) e da já mencionada Anistia Internacional. O relatório Você matou meu filho - Homicídios cometidos pela Polícia Militar na cidade do Rio de Janeiro (ANISTIA INTERNACIONAL, 2015) é exemplo disso.

Embora haja exemplos interessantes de articulação das vozes faveladas a fim de ampliar seu poder de denúncia dessas tantas violações - como parece ser o caso do portal de relatos das favelas cariocas RioOnWatch, idealizado pela organização não-governamental Comunidades Catalisadoras (ComCat) -, é nas redes digitais, por meio de suas postagens, que a maior parte daqueles que moram nas favelas consegue destacar suas iniciativas que, estrategicamente, visam a maiores chances de participação cidadã (MAIA, 2017, p. 24). Para além das inúmeras situações em que se evidencia o desrespeito aos direitos humanos, elas têm atuado de forma relevante, inclusive, na divulgação de certos produtos locais de cultura popular ainda não assimilados pelas dinâmicas mais amplas do mercado de bens simbólicos, permitindo que tais conteúdos sejam expandidos em rede de tal forma que, muitas vezes, subvertam a dinâmica de consumo imposta pelas corporações que dominam a economia das mídias. No caso das favelas, essa compreensão é ainda mais verdadeira e pode ser percebida em diferentes performances em meio digital.

A carioca Luane Dias, por exemplo, moradora da favela da Cidade Alta, chegou a fazer parte do elenco do programa Esquenta!, apresentado por Regina Casé na TV Globo, em função do vídeo amador que gravou em sua própria casa sobre o comportamento assumido por algumas garotas ao usarem o Facebook (MAIA; BRAGA, 2017). Além dela, em 2015, o grupo MC Federado e os Leleques, formado por jovens do subúrbio do Rio de Janeiro, publicou na plataforma digital YouTube um clipe amador da canção Passinho do volante. Essa modalidade de dança, o passinho, é descrito por Pereira de Sá (2014) como

um desafio entre jovens moradores de favelas e comunidades da cidade do Rio de Janeiro que executam passos de dança complexos, misturando a coreografia do funk a outros gêneros tais como o frevo, o tango e/ou passo do moonwalk de Michael Jackson, dançados ao som de celulares e gravados e editados de maneira amadora. (PEREIRA DE SÁ, 2014, 29).

10. O BOPE, Batalhão de Operações Policiais Especiais, é uma divisão da PMERJ treinada para agir em situações de risco e que tem atuado recorrentemente nos contextos de favela. Simbolizado por uma caveira atravessada por uma faca, é costumeiramente reconhecido como o órgão mais violento da polícia carioca. 
Dias depois, o vídeo postado pelo grupo tornou-se um sucesso nacional. Uma prática cultural como essa, que ganha visibilidade em função do potencial de produção de conteúdos multissemióticos e de comunicação interligada dos recursos digitais, reforça o fato de que estas são mediadoras importantes não só na busca por direitos humanos das minorias, mas também por direitos culturais. Se é verdade que a diversidade cultural deve ser valorizada, tal como aponta a Declaração Universal sobre a Diversidade Cultural (UNESCO, 2002), as tecnologias digitais, mesmo com os diferentes tipos de restrições técnicas que carregam consigo, têm justamente funcionado como ferramentas indispensáveis para a promoção dessa diversidade e para o contato entre práticas culturais de diferentes localidades do mundo.

Não podemos ignorar, por fim, que essas postagens requerem a mobilização de inúmeros letramentos, complexamente praticados por esses agentes que, socialmente, costumam ser estereotipados como incapazes, como improdutivos, como péssimos leitores, como analfabetos. Nesse sentido, inspirado pela compreensão do filósofo Jacques Derrida (1979, p. 89) de que toda escrita é sobrevivente, creio que os textos, as gravuras, os sinais, enfim, os produtos semióticos elaborados pelos moradores da maior parte dos contextos suburbanos ou favelados do Brasil sejam, assim como seus autores, sobreviventes. Por isso, passo a tratar agora do que entendo como letramentos de sobrevivência e de como eles são praticados sobretudo nas redes digitais, considerando-as como canais que têm sido fundamentais para que novas formas de mobilização social por direitos humanos e de participação cidadã emerjam na tão desigual realidade brasileira.

\section{COMO QUE VAI SE CALAR DIANTE DISSO?: ENUNCIANDO SOBREVIVÊNCIAS EM REDES DIGITAIS NA LUTA POR DIREITOS HUMANOS}

Considerando que a circulação de narrativas que tratam de violações de direitos humanos não tem sido de interesse das mídias corporativas, as tecnologias digitais, mesmo com suas limitações, acabam assumindo um papel fundamental nessa dinâmica na medida em que permitem o estabelecimento de redes alternativas de informação e de comunicação, capazes de denunciar violações de direitos humanos que estariam fadadas ao silenciamento. A própria postagem feita no Facebook pela Mídia NINJA e que registrei anteriormente é exemplo disso, assim como o excerto seguinte, transcrito a partir de um encontro do qual participei no Museu Nacional, em 2015, no âmbito do curso "Sobreviver, sobrevivências", ministrado pelas professoras Adriana Facina e Adriana Carvalho Lopes em conjunto com o professor Daniel do Nascimento e Silva. 
Naquela oportunidade, Mariluce Mariá Souza e Cléber Santos, casal de moradores do Complexo do Alemão que participou de minha pesquisa de doutorado (MAIA, 2017) em função de seu protagonismo na luta por direitos humanos e culturais para sua comunidade, fizeram reflexões sobre o porquê de tamanha rejeição dos favelados em relação ao projeto implantado das UPPs, mesmo diante das muitas falas positivas - praticamente unânimes nos meios de comunicação das mídias corporativas - sobre tal iniciativa.

[01:25:27] Cléber: E tem outro agravante. Qual a responsabilidade social, qual a responsabilidade ética, qual a responsabilidade física que o bandido tem com a pessoa? Nenhuma!

[01:25:37] Mariluce: Bandido não recebe salário do Estado pra tá lá.

[01:25:40] Cléber: Agora, quando a pessoa da favela fala "Fora tráfico!", por quê? O cara, ele veste a farda do Estado, tem uma carteirinha do Estado, ele representa o Estado ali naquele momento, o Estado que tá ali presente. "Ah, porque o policial é coitadinho!". Não, ele não é o coitadinho, ele quis ser polícia, ele entrou na polícia porque sabe que tem muitas facilidades, tem muitos benefícios, né, que o policial tem, hoje, no Rio de Janeiro, nós sabemos disso, no Brasil inteiro, inclusive. Então, o cara, ele não é obrigado a ser policial, ele vai porque quer. Quando ele vai pra favela, pior ainda, aumenta esse índice mais ainda. Então, quando a gente fala, lá na favela, fala "Fora UPP!", é pro Estado, para as pessoas lá fora acender um alerta e falar, "O que é que esse povo tá falando, Fora UPP!"? Que que tá acontecendo? 38

[01:26:21] Adriana Facina: Quebrar esse consenso, né? Porque você só vê coisa boa sobre a UPP.

[01:26:24] Cléber: Né? Só vê coisa boa. "A UPP salvou". Não salvou coisa nenhuma, entendeu?

[01:26:29] Mariluce: A internet salvou a gente mais do que UPP.

[01:26:33] Cléber: A gente fala assim, poxa, o cara tá aqui, se autointitula a segurança pública do Estado, o cara recebe do Estado, pago com o meu salário, o cara vem aqui pra dar tiro à toa? Jogar bomba, igual o cara tá jogando, os caras tão jogando lá na UPP do Alemão, jogando bomba! Entendeu? Pega o cabeção de nego, aquelas bombona grandona, e joga! Ô, meu irmão, que que é isso? Que representatividade que esse cara tá tendo? O cara chega na favela gritando "Eu sou o demônio! Eu 
quero beber sangue!", entendeu? Como? Como que você vai se calar diante disso? Não tem como!

Em sua segunda fala, logo de início, Cléber pratica um curioso ato falho ao confundir os referentes, utilizando o termo "tráfico" em lugar de seu significante contextual supostamente oposto, "UPP". Ao efetuar essa troca metafórica, o morador acaba criando uma associação entre as práticas de ambos os agentes com base nos elementos corrupção e violência. Nesse sentido, ainda que inconscientemente, ele parece não só enunciar a sua vontade e a de seus vizinhos de que não exista qualquer praticante de irregularidades no território da favela, como também indiciar, por consequência, como é falaciosa a ideia, cara aos residentes no asfalto, de que só os varejistas de drogas - o "tráfico - cometem delitos; as instituições policiais, por conseguinte, também são criminosas. Nesse sentido, em meio ao embate - mortal, em muitos casos - produzido no território pela corrupção e pela disputa de forças, o morador é obrigado a sobreviver.

Além disso, Cléber reconhece justamente o heterogêneo e o eventual que caracterizam uma intervenção violenta do Estado em sua realidade. Sua reivindicação é pautada, todavia, no fato de que situações em que os policias agem com violência e em desacordo com suas funções pressupostas têm sido cada vez mais recorrentes, fazendo com que a vida cotidiana no Complexo do Alemão seja constantemente atravessada por narrativas sobre a morte de alguém que reside na favela. Nesse sentido, a expansão de enunciados de sobrevivência via redes digitais torna-se fundamental para o poder de ação política por parte dos moradores: parodiando o famoso Rap do Silva, de autoria do MC Bob Rum, o Facebook não é modismo, é uma necessidade.

Desse modo, o caráter expansionista do compartilhamento de informações em função da entextualização ${ }^{11}$ de enunciados, sobretudo via Facebook e twitter, é o que tem contribuído para que as lutas sociais praticadas pelos moradores do Complexo do Alemão extrapolem os seus limites geográficos. As postagens por eles produzidas em redes digitais acabam alcançando audiências diversificadas, assumindo um caráter translocal - nos termos de Blommaert (2010) - que representa uma grande chance de desestabilização de escritas hegemônicas e de consequente ampliação das possibilidades de participação cidadã por parte desses agentes em variadas esferas sociais.

11.A entextualização, conforme Bauman e Briggs (1990, p. 73), consiste no processo de fazer um determinado texto transitar de uma situação discursiva para outra, carregando consigo elementos de sua história e ressignificando-os por meio de uma hibridização com as características do novo contexto em que passa a circular. 
Um exemplo de situação marcada por essa dinâmica envolvendo redes digitais e denúncias de abusos praticados no território foi o tuitaço ${ }^{12}$, de cuja organização Mariluce e Cléber participaram, que alavancou a hasbtag \#SOSComplexodoAlemao aos trending topics do Brasil no dia 12 de agosto de 2014. Naquela época, pouco tempo após a finalização da Copa do Mundo, o BOPE invadiu o Complexo do Alemão e desencadeou uma série de tiroteios, provocando a morte de cerca de 10 pessoas lá residentes. Diante do costumeiro silêncio das mídias corporativas, o casal buscou apoio de outros moradores e de especialistas em redes sociais a fim de, por meio de uma ação conjunta e orquestrada, fazer circular amplamente no meio digital pedidos de socorro e denúncias de abusos concentrados em uma basbtag.
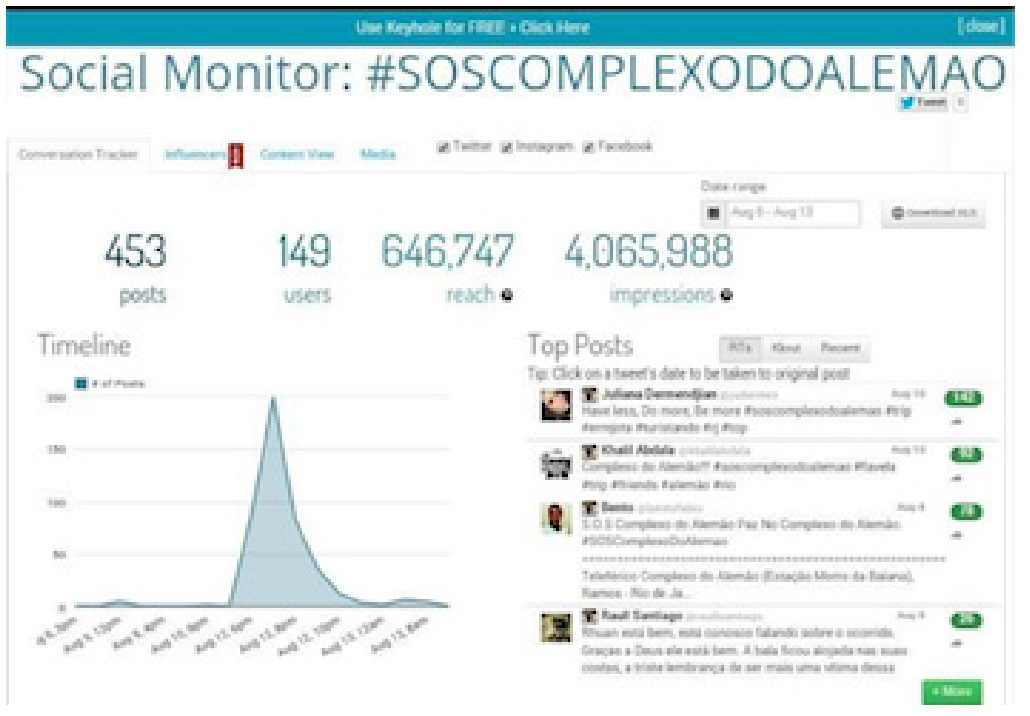

Figura 2. Postagem de Mariluce Mariá sobre o tuitaço \#SOSComplexodoAlemao. Fonte: Acervo pessoal.

A iniciativa dos moradores, que mobilizou usuários de redes digitais como o Facebook e o twitter, conseguiu gerar um impacto significativo naquele dia. No total, a bashtag \#SOSComplexodoAlemao atingiu diretamente mais de 646 mil pessoas, além de apresentar um potencial de alcance de cerca de 4 milhões de internautas. Diante desse panorama de entextualizações translocais, chamo atenção para o fato de que as

12.Em linhas gerais, um tuitaço pode ser entendido como uma série de postagens com finalidade comum organizadas em uma hashtag. Embora seu nome decorra do twitter, ele ocorre também em outras redes sociais, principalmente o Facebook. Trata-se, pois, de um exemplo interessante de convergência entre mídias digitais (JENKINS, 2015 [2006]). 
postagens feitas pelos favelados do Complexo do Alemão enunciam a existência de um cotidiano de luta constante pela persistência e pela valorização da vida naquela região. Os moradores, de forma similar às ideias de Bhabha (2013 [1994]), por meio de suas diversas práticas sociais e culturais, enunciam a existência de uma cultura de sobrevivência (BHABHA, 2013 [1994], p. 277). Em linhas gerais,

[a] cultura como estratégia de sobrevivência é tanto transnacional como tradutória. Ela é transnacional porque os discursos pós-coloniais contemporâneos estão enraizados em histórias específicas de deslocamento cultural, seja como "meia-passagem" da escravidão e servidão, como "viagem para fora" da missão civilizatória, a acomodação maciça da migração do Terceiro Mundo para o Ocidente após a Segunda Guerra Mundial, ou o trânsito de refugiados econômicos e políticos dentro e fora do Terceiro Mundo. A cultura é tradutória porque essas histórias espaciais de deslocamento - agora acompanhadas pelas ambições territoriais das tecnologias "globais" de mídia - tornam a questão de como a cultura significa, ou o que é significado por cultura, um assunto bastante complexo. (BHABHA, 2013 [1994], p. 277).

Nesse sentido, essa cultura de sobrevivência se materializa em enunciados que denunciam as situações de opressão existentes no Complexo do Alemão simbolizadas majoritariamente pelos aparelhos de repressão do aparato estatal -, mas que também registram a resistência desses sujeitos diante das adversidades, suas táticas para subversão de uma lógica do controle e da agressão alicerçadas pela cultura do asfalto. Podem, desse modo, ser interpretados como enunciados transnacionais, pois praticam o deslocamento cultural na medida em que agem no terreno do outro-colonizador a partir do momento em que se expandem. A própria metáfora do Complexo do Alemão como "Faixa de Gaza" carioca, aliás, sustenta-se por esse caráter transnacional: situações de violência tangentes a remoções realizadas em função do PAC apresentam inúmeros pontos de convergência com a situação palestina, por exemplo, marcada por iniciativas de mesma natureza, violadoras de direitos humanos e culturais. Além disso, apresentam caráter tradutório uma vez que, ao mesmo tempo em que tornam complexas as relações de deslocamento e de pertencimento praticadas pelos moradores, fazem com que as ações de violência e de resistência ocorrentes em seu cotidiano sejam ressignificadas a partir de outros olhares, de outras interpretações praticadas pelo outro.

Essa reflexão, um tanto complexa, é traduzida no depoimento dado pelo jovem favelado MC Calazans - registrado academicamente no trabalho de Facina (2014) - durante encontro promovido pelo Instituto Raízes em Movimento sobre políticas públicas e cultura.

Não existiria o Complexo do Alemão se não fosse a cultura. E a cultura não só a cultura artística do grafite, do rap, do pagode, do samba. Não, eu acho que é uma cultura da sobrevivência. Por exemplo, o gatonet. O gatonet nada mais é do que uma cultura de universalizar o acesso à internet. O gatoluz nada mais é do que uma cultura da sobrevivência para universalizar o acesso à luz. 
Cultura da favela, do Complexo do Alemão principalmente, ela sempre veio da solidariedade. Então é assim: se você que mora embaixo do morro tem uma internet, o cara que mora aqui no pico da Grota tem que ter. Então pega os fiozinhos, vai engatando até chegar lá. Se você mora no pé do morro e tem saneamento básico, mano, puxa um caninho lá da puta que o pariu e vem emendando, fazendo gato, passando perrengue. Então essa cultura, que é o que acho mais importante, foda, incrível, essa cultura da sobrevivência fundada numa solidariedade, uma identidade de irmandade mesmo, que eu acho assim que é a mais... que poucas pessoas valorizam isso e quando valorizam é para legalizar: "vamo botar TV por assinatura, vamos acabar com os gatonets..." Quando isso é uma cultura que o morro criou. Lan bouses, né, que foram criadas na própria favela para dar acesso à internet, mototáxi... Então a primeira cultura que a gente tem é uma cultura da sobrevivência. A gente tem uma realidade difícil, então, como vamos superar ela? Uma das formas de superar é construir uma cultura local. Fora isso, a parte mais tradicional da cultura, isso daqui, cara, é um celeiro de artistas. Artistas tanto do grafite, do pagode, do samba. Você tem a quadra da Imperatriz aqui na Pedra do Sapo, lá do início - isso eu sei por causa que os meus avós iam, foram uns dos fundadores de lá - e era o encontro dos neguinhos com cachaça e violão, fazendo música, fazendo samba. Não tinha luz no Complexo do Alemão, era tudo roça. Aí começou dali. Cada beco daqui tem uma certa identidade. (FACINA, 2014, pp. 40-41).

A fala de MC Calazans expõe a maneira como essa cultura de sobrevivência, estabelecida na tensão entre a opressão e a resistência, surge a partir do híbrido, da articulação de práticas culturais para sobreviver pelos becos. Nessa direção, a sobrevivência se constrói, assim como Bhabha (2013 [1994]) nos aponta, na "meiapassagem" de um histórico marcado pela escravidão e pela servidão, que ainda apresenta os seus reflexos na contemporaneidade, e pelas ações de luta social dos moradores de favela, que agem no sentido de legitimar suas manifestações de cultura diante da opressão exercida pelos grupos de poder - no caso, Estado controlador, classes mais abastadas e corporações de grande mídia, principalmente.

Em seu turno, os enunciados combativos produzidos pelos moradores do Complexo do Alemão são produtos, portanto, de letramentos de sobrevivência. Esse conceito - proposto por Adriana Carvalho Lopes e colegas em artigos recentes (LOPES; SILVA; FACINA， 2014; LOPES; SILVA; FACINA; CALAZANS; TAVARES, 2017, 2018) e também desenvolvido em minha tese de doutorado $\left(\right.$ MAIA, 2017) ${ }^{13}$ - decorre da percepção de que a sobrevivência atravessa a constituição desses letramentos e faz com que os textos produzidos com base neles

13. O conceito de letramentos de sobrevivência, cunhado por Adriana Carvalho Lopes, é produto do trabalho de campo pertinente ao projeto de pesquisa "Mapeamento da produção cultural e das práticas de letramento em três favelas do Complexo do Alemão". Liderado pela antropóloga Adriana Facina, esse projeto agregou diferentes pesquisas interessadas em analisar práticas culturais características do território do Complexo do Alemão. Não é sem razão, portanto, que os trabalhos dele decorrentes sejam fortemente marcados por colaboração e coletividade, algo que se evidencia, inclusive, em todas essas referências teóricas que acabo de mencionar.ele caráter colaborativo que acompanhou o desenrolar de todo esse projeto é o responsável por fazer com que boa parte das reflexões e proposições teóricas dele decorrentes tenham sido elaboradas 
emerjam de um cotidiano em que a violência se manifesta das mais diversas formas, com as mais variadas forças. Tais enunciados, desse modo, se contrapõem aos silenciamentos e estereotipizações que culturas dominantes, legitimadas pelo poder instituído e residentes no asfalto, buscam impor incessantemente aos favelados, bárbaros relegados aos desmandos e às arbitrariedades dos agentes estatais de repressão. Letramentos de sobrevivência são, portanto, práticas sociais que, fundamentalmente, testemunham violações de direitos humanos e culturais e que, enunciados, questionam polaridades, contaminam a homogeneidade de iniciativas hegemônicas e, assim, entextualizam histórias contadas e escovadas a contrapelo, nos termos postos por Walter Benjamim na tese 7 de seu texto Sobre o conceito de bistória (2012 [1985], p. 245).

Nesse sentido, eles motivam escritas e outras práticas culturais capazes de confrontar escritas que criminalizam e violentam os cidadãos da favela e estabilizam o asfalto - metonímia referente às áreas legalizadas e autorizadas existentes na cidade - como modelo válido e valorizado de moradia no espaço urbano. Intervindo, pois, nessas estruturas dominantes e impondo desarticulações e reconfigurações em sua dinâmica, acabam implicando a enunciação de outras narrativas, relatos contrahegemônicos que, no caso da cidade carioca, questionam a primazia de lógicas exploradoras e excludentes que persistem desde os tempos coloniais.

Essa intervenção, a meu ver, se estabelece por meio de uma ruptura que, pensada a partir de Derrida (1977), transpõe o que se pretende homogêneo nas escritas autorizadas, ao mesmo tempo em que as ressignifica. Trata-se, nesse sentido, de uma ação calcada na prática da hibridação, uma contaminação da sistêmica dominante que simboliza o antigo em função de uma nova perspectiva e que instaura o novo sob uma lógica mais permeável e fronteiriça. Dessa compreensão decorre, por exemplo, as possibilidades translocais e tradutórias que marcam o potencial de iterabilidade ${ }^{14}$ dos produtos desses letramentos: eis, pois, o ponto crucial em que os limites entre escritas de sobrevivência, que desestabilizam a oposição vida e morte ao enunciar a própria violência que as motiva, e tecnologias digitais conectadas se tornam mais tênues e permeáveis.

A maneira como as tecnologias digitais intensificam conexões em tempos de globalização facilita a expansão - a entextualização, em termos mais específicos dessas escritas impuras (GARCÍA CANCLINI, 2011 [1997], p. 284; MAIA, 2013,

14.Em síntese, a iterabilidade pode ser entendida como uma repetição que desloca e quebra, uma possibilidade estrutural da linguagem em que o signo rompe com o seu contexto original quando é citado, viabilizando sentidos outros e moldando ilimitadamente novos contextos (SILVA, 2012, p. 21). 
p. 45) por redes sociais que se estabelecem em função do uso da internet. $\mathrm{O}$ advento das mídias locativas, como é o caso dos tablets e smartphones, foi fundamental para que a internet passasse a acompanhar o usuário aonde quer que ele fosse, ampliando, assim, suas possibilidades de participação em diversas redes a partir de uma lógica translocal. Nesse sentido, a semioticista Lúcia Santaella (2008) propõe a metáfora dos espaços intersticiais para esclarecer o que de fato há de inovador nas atuais dinâmicas de comunicação, que já não funcionam com base em estruturas rígidas e binarismos fixos, principalmente no que tange a questões de localidade.

Os espaços intersticiais referem-se às bordas entre espaços físicos e digitais, compondo espaços conectados, nos quais se rompe a distinção tradicional entre espaços físicos, de um lado, e digitais, de outro. Assim, um espaço intersticial ou híbrido ocorre quando não mais se precisa "sair" do espaço físico para entrar em contato com ambientes digitais. Sendo assim, as bordas entre os espaços digitais e físicos tornam-se difusas e não mais completamente distinguíveis. (SANTAELLA, 2008, p. 21).

Os espaços intersticiais, portanto, relativizam a necessidade do contato físico para intervenção na realidade e para interação entre as pessoas. Situações em que um morador de favela é intimidado por um policial e inicia um vídeo ao vivo em seu perfil do Facebook como estratégia de denúncia são exemplos de como os usuários têm se posicionado cada vez mais nessas bordas entre o concreto e o digital para buscar efeitos que transpõem essa oposição. Uma situação como essa, ainda, dá relevância também às potencialidades multissemióticas dessas ferramentas, que exploram diferentes processos de produção de sentido que vão além da hegemonia do mundo no papel (OLSON, 1994), tão tradicional nos tempos analógicos.

Entendo, é claro, que a ubiquidade de conexão e a posse de aparatos de tecnologia digital estão sujeitas a disparidades sociais macroestruturais. Não posso me furtar, todavia, a reconhecer que, em contextos urbanos atravessados pela lógica da globalização, como é o caso do Rio de Janeiro, o acesso à internet tem sido crescente e, por conseguinte, cada vez mais universalizado. Por isso, acato essa interpretação relativa aos letramentos de sobrevivência e entendo que, no contexto do Complexo do Alemão, o aumento considerável da circulação dos produtos dessas práticas de escrita tem se dado principalmente em função da maneira como as tecnologias digitais conectadas viabilizam o trânsito de um texto por variadas cadeias de entextualização que ampliam chances de rompimentos e rupturas nas escritas que criminalizam os moradores de favelas. 


\section{CONSIDERAÇÕES FINAIS}

No Complexo do Alemão, assim como acontece na maior parte das periferias urbanas do Brasil, as mídias digitais têm sido amplamente utilizadas como instrumentos de denúncia da maneira como policiais, especialmente aqueles que fazem parte das UPPs, têm agido de forma arbitrária, agressiva e, muitas vezes, mortal em relação aos moradores. Mas a vida, mesmo em um contexto em que a morte costuma ser frequente e banalizada, consegue se reinventar e continuar (r) existindo; insiste, nas palavras de Caetano Veloso, em ser amiga da arte, como quando reiterada em manifestações culturais genuínas da favela, como o funk.

\footnotetext{
(...)

Mas essa noite comeu solto o tiroteio

Favela tava cercada, não tinha como sair

E a criançada atrás da porta em desespero

Pelo amor de Deus, papai, tira a gente daqui

Aí então uma lágrima desceu

Eu vi que minha força vinha da força de Deus

Só peço ao moço antes de apertar o gatilho

Que pense nos seus filhos antes de matar os meus

E triste amigo a gente chegar do trabalho

E ser esculachado por um motivo que eu nem sei

O rico sente pena, mas sentir pena é fácil

Ninguém passou na pele a humilhação que passei

(DOCA; ANDINHO; CIDINHO, 2001)
}

Nessa canção, intitulada Meus Direitos (DOCA; ANDINHO; CIDINHO, 2001), os MCs Cidinho e Doca, em parceria com o também funkeiro Andinho, fazem da música instrumento de denúncia e de relato da opressão. Em versos, narram situações de violência a que favelados estão sujeitos, marcadas por tiroteios, por cerceamentos de liberdade e pelo corriqueiro esculacho, que, em síntese, corresponde à abordagem abusiva e humilhante praticada pelos policiais. Uma súplica por alteridade, que destaquei por meio de negrito, esclarece quem, na favela, pode matar e quem deve morrer.

Ameaçados de morte, ofunk, na incansável mira do conservadorismo estético, e o favelado, na mira dos fuzis, precisam de instrumentos que lhes garantam possibilidades mais consistentes e expansivas de luta por direitos culturais e humanos. Como venho propondo ao longo deste texto, postagens em redes digitais têm cumprido esse papel, permitindo novas interações entre moradores de favela e fazendo ecoar, a despeito das persistentes barreiras estruturais, gemidos que, em 1995, ano em que MC Bob Rum compôs o já citado Rap do Silva, eram ainda mais calados e silenciados no ambiente da cidade carioca. 


\section{REFERÊNCIAS}

ANISTIA INTERNACIONAL. (2015) Você matou meu filbo - Homicídios cometidos pela Polícia Militar na cidade do Rio de Janeiro. Rio de Janeiro: Anistia Internacional.

AUSTIN, J. L. (1962) How to do things with words. 2nd. Edition. Oxford: The Clarendon Press, 1975.

BAUMAN, R.; BRIGGS, C. (1990) Poetics and performance as critical perspectives on language and social life. In: Annual Review of Antbropology, v. 19. Palo Alto: Annual Reviews, pp. 59-88.

BENJAMIN, W. (1985) Sobre o conceito de história. In: Magia e técnica, arte e política: ensaios sobre literatura e bistória da cultura. Tradução de Sérgio Paulo Rouanet. 8 a ed. revista, Obras Escolhidas v.1. São Paulo: Brasiliense, 2012, pp. 241-252.

BHABHA, H. K. (1994) O local da cultura. Tradução de Miriam Ávila et. al. Belo Horizonte: Editora da UFMG, 2013.

BLOMMAERT, J. (2010) The sociolinguistics of globalization. Cambridge: Cambridge University Press.

BRUNS, A.; BURGESS, J. (2011) The use of twitter hashtags in the formation of Ad Hoc publics. Paper presented at the European Consortium for Political Research conference. Reykjavik: ECPR, pp. 1-9.

COELHO, H. (2016) Processo contra PMs acusados de matar menino Eduardo, no Alemão, é arquivado. In: G1. Disponível em: https://g1.globo.com/rio-de-janeiro/noticia/ processo-contra-pms-acusados-de-matar-menino-eduardo-no-alemao-e-arquivado. ghtml. Último acesso em 24 de junho de 2018.

CRISAFULLI, L. (2016) Derecho penal, criminología y los muertos. Una introducción a Zaffaroni. In: CRISAFULLI, L. (Ed.) Derechos bumanos y poder: conversaciones con Zaffaroni. Córdoba: Universidad Nacional de Córdoba, pp. 27-70.

DAS, V.; POOLE, D. (2004) Anthropology in the margins of the State. In: PoLAR: Political and Legal Antbropology Review, V. 30, N. 1. Arlington: Association for Political and Legal Anthropology, pp. 140-144.

D’EliA FILHO, O. Z. (2007) Acionistas do nada: quem são os traficantes de drogas. $3^{\text {a }}$ Ed., $2^{\text {a }}$ Reimpressão. Rio de Janeiro: Revan, 2015. 
DERRIDA, J. (1977) Signature event context. Tradução: Samuel Weber e Jeffrey Mehlam. In: Glyph, Vol.1., pp. 172-197.

DERRIDA, J. (1979) Living on. In: BLOOM, H. et al. Deconstruction and Criticism. New York: Seabury Press, pp. 75-176.

DOCA; ANDINHO; CIDINHO. (2001) Meus direitos. Guarulhos: EMI Music Ltda, 1 disco sonoro.

FACINA, A. (2014) Sobreviver e sonhar: reflexões sobre cultura e "pacificação" no Complexo do Alemão. In: PEDRINHA, R. D.; FERNANDES, M. A. (Orgs.). Escritos transdisciplinares de criminologia, direito e processo penal: bomenagem aos mestres Vera Malaguti e Nilo Batista. Rio de Janeiro: Revan, pp. 39-48.

FOLHA DE S. PAULO. (2013) Polícia investiga desaparecimento de pedreiro na Rocinha, no Rio. Disponível em: http://www1.folha.uol.com.br/cotidiano/2013/07/1313319policia-investiga-desaparecimento-de-pedreiro-na-rocinha-no-rio.shtml. Último acesso em 12 de Março de 2018.

GARCÍA CANCLINI, N. (1997) Culturas bíbridas: estratégias para entrar e sair da modernidade, $4^{a}$ Ed, $5^{a}$ Reimpr. São Paulo: Editora da Universidade de São Paulo, 2011.

LOPES, A. C.; SILVA, D. N.; FACINA, A. (2014) Letramentos de ruptura: as escritas do funk carioca. In: Anais do V Colóquio Letramento e Cultura Escrita, V. 1. Belo Horizonte: CEALE/UFMG, pp. 1-9.

LOPES, A. C.; SILVA, D. N.; FACINA, A.; CALAZANS, R.; TAVARES, J. (2017) Desregulamentando dicotomias: transletramentos, sobrevivências, nascimentos. In: Trabalbos em Linguística Aplicada, V. 56, n. 3. Campinas: IEL/UNICAMP, pp. 753-780.

LOPES, A. C.; SILVA, D. N.; FACINA, A.; CALAZANS, R.; TAVARES, J. (2018) Letramentos de sobrevivência: costurando vozes e histórias. In: Revista da ABPN, $V$. 10. Goiânia: Associação Brasileira de Pesquisadores Negros (ABPN), pp. 678-703.

MAIA, J. O. (2013) Apropriação dos letramentos digitais para participação social mais ampla: um estudo de caso. Dissertação de mestrado. Campinas: IEL/UNICAMP.

MAIA, J. O. (2017) Fogos digitais: letramentos de sobrevivência no Complexo do Alemão. Tese de doutorado. Campinas: IEL/UNICAMP.

MAIA, J. O.; BRAGA, D. B. (2017) Popularidade e visibilidade em redes sociais online: negociação de capitais sociais em meio digital para ampliação de audiência. In: Signótica, V. 29, n. 2. Goiânia: UFG, pp. 354-376. 
MALAGUTI BATISTA, V. (2011) Introdução à criminologia crítica brasileira. Rio de Janeiro: Revan.

OLIVEIRA, B. C. S. (2018) "Não tem essa de separação, aqui é tudo Complexo do Alemão!": uma etnografia dos espaços urbanos em um conjunto residencial no Rio de Janeiro. Tese de doutorado inédita em Sociologia. Rio de Janeiro: Instituto de Estudos Sociais e Políticos/UERJ.

OLSON, D. R. (1994) O mundo no papel: as implicações conceituais e cognitivas da leitura e da escrita. Tradução de Sérgio Bath. São Paulo: Ática, 1997.

PASSOS, P. S.; FACINA, A. (2014) Cultura popular e direitos bumanos. Rio de Janeiro: DDH.

PEREIRA DE SÁ, S. (2014) Apropriações low-tech no funk carioca: a Batalha do Passinho e a rede de música popular de periferia. In: Revista Fronteiras - Estudos midiáticos, V. 16, N. 1. São Leopoldo: Unisinos, pp. 28-37.

SANTAELLA, L. (2008) A ecologia pluralista nas mídias locativas. In: Revista FAMECOS -Mídia, cultura e tecnologia, V. 3, n. 37. Porto Alegre: EdiPUCRS, pp. 20-24.

SECCO, L. (2013) As jornadas de junho. In: MARICATO, E. et al. Cidades rebeldes: Passe Livre e as manifestações que tomaram as ruas do Brasil. São Paulo: Boitempo; Carta Maior, pp. 71-78.

SHIRKY, C. (2008) Lá vem todo mundo: o poder das organizações sem organizações. Tradução: Maria Luiza X. de A. Borges. Rio de Janeiro: Zahar, 2012.

SILVA, D. N. (2012) Pragmática da violência: o Nordeste na mídia brasileira. Rio de Janeiro: 7 Letras, FAPERJ.

SUSSMAN, N. (2015) In Rio, pacification without peace (8m33s). Disponível em: https://www. youtube.com/watch?v=oVgy0apgIVI. Último acesso em 24 de junho de 2018.

UNESCO. (2002) Declaração Universal sobre a Diversidade Cultural. Disponível em: http:// unesdoc.unesco.org/images/0012/001271/127160por.pdf. Último acesso em 08 de Abril de 2017.

ZAFFARONI, E. R. (2002) Derecho penal - Parte general. Buenos Aires: Ediar.

Recebido: 12/03/2018

Aceito: 9/07/2018 